\title{
Verification of consumers' experiences and perceptions of genetic discrimination and its impact on utilization of genetic testing
}

\author{
Kristine Barlow-Stewart, PhD ${ }^{1,2}$, Sandra D. Taylor, PhD ${ }^{3}$, Susan A. Treloar, PhD ${ }^{4}$, \\ Mark Stranger, $P h D^{5}$, and Margaret Otlowski, $P h D^{5}$
}

\begin{abstract}
Purpose: To undertake a systematic process of verification of consumer accounts of alleged genetic discrimination. Methods: Verification of incidents reported in life insurance and other contexts that met the criteria of genetic discrimination, and the impact of fear of such treatment, was determined, with consent, through interview, document analysis and where appropriate, direct contact with the third party involved. The process comprised obtaining evidence that the alleged incident was accurately reported and determining whether the decision or action seemed to be justifiable and/or ethical. Results: Reported incidents of genetic discrimination were verified in life insurance access, underwriting and coercion (9), applications for worker's compensation (1) and early release from prison (1) and in two cases of fear of discrimination impacting on access to genetic testing. Relevant conditions were inherited cancer susceptibility (8), Huntington disease (3), hereditary hemochromatosis (1), and polycystic kidney disease (1). In two cases, the reversal of an adverse underwriting decision to standard rate after intervention with insurers by genetics health professionals was verified. The mismatch between consumer and third party accounts in three life insurance incidents involved miscommunication or lack of information provision by financial advisers. Conclusion: These first cases of verified genetic discrimination make it essential for policies and guidelines to be developed and implemented to ensure appropriate use of genetic test results in insurance underwriting, to promote education and training in the financial industry, and to provide support for consumers and health professionals undertaking challenges of adverse decisions. Genet Med 2009:11(3):193-201.
\end{abstract}

Key Words: genetic discrimination, life insurance, law, inherited cancers, Huntington disease

W idespread concern has been expressed regarding the potential impact on individuals and families of "genetic discrimination"1 (GD) defined as the differential treatment of an asymptomatic person solely on the basis of their genetic char-

From the ${ }^{1}$ Centre for Genetics Education, NSW Health, Royal North Shore Hospital, Sydney, Australia; ${ }^{2}$ Faculty of Medicine, University of Sydney, Australia; ${ }^{3}$ Centre for Social Science Research, Central Queensland University, Rockhampton, Australia; ${ }^{4}$ Centre for Military and Veterans' Health, The University of Queensland, Brisbane, Australia; and ${ }^{5}$ Centre for Law and Genetics, University of Tasmania, Hobart, Australia

Kristine Barlow-Stewart, PhD, Centre for Genetics Education, NSW Health, Royal North Shore Hospital, St Leonards NSW 2065, Australia. E-mail: kbarlow@med.usyd.edu.au.

Disclosure: The authors declare no conflict of interest.

Supplemental digital content is available for this article. Direct URL citations appear in the printed text and are provided in the HTML and PDF versions of this article on the journal's Web site (www.geneticsinmedicine. org).

Submitted for publication May 24, 2008

Accepted for publication November 10, 2008

DOI: 10.1097/GIM.0b013e318194ee75 acteristics predicted from a genetic test result or their family history. Accounts of alleged GD in life and/or health insurance and employment contexts have been reported in Australia, ${ }^{2-4}$ the United States, ${ }^{5-7}$ the United Kingdom ${ }^{8}$ and Europe. ${ }^{9}$

Most accounts of GD to date have been based on anecdotal or unverified data causing some commentators to question if the phenomenon actually exists and is instead a measure of "genetic dread" in society. ${ }^{10}$ In Australia, the need for empirical evidence regarding GD to inform policy and law has been identified $^{11}$ and in 2002, the Genetic Discrimination Project (GDP) ${ }^{1}$ was initiated to address the lack of empirical data. Of triangulated design, it has comprised the key subprojects of Consumer, Third Party, Legal System, and Verification Studies, ${ }^{12}$ with Verification Project findings being the focus of this article. A strong consultative Expert Reference Group supported the interdisciplinary GDP research team and relevant Human Research Ethics Committee approvals were obtained.

The GDP Consumer Study analyzed survey responses from 951 asymptomatic individuals who had attended an Australian clinical genetics service (1998-2003) regarding predictive or presymptomatic testing for a range of conditions. ${ }^{3}$ Perceived incidents of negative or unfair treatment were reported by 93 individuals $(10 \%$ prevalence) in insurance and employmentrelated domains (50 times), in informal family and social contexts (38 times) and within health services (22 times). . $^{3,4}$

GD-related issues within insurance and employment were also investigated within the GDP Third Party Study. Regarding employment, ${ }^{13}$ although there were significant challenges to obtaining a complete picture of employer respondents' use of genetic information, findings seemed quantitatively consistent with those from the GDP Consumer Study that suggest a low current prevalence of GD in the Australian employment domain. , $^{3,4}$

Regarding insurance, an independent analysis was conducted of Australian life insurance industry data: 288 applications (1999-2003) where genetic test results were disclosed. ${ }^{14} \mathrm{Ge}-$ netic testing was the only influencing factor on the underwriting decision in $49 \%$ of cases: the decisions seemed reasonable for the majority but unjustified in three cases involving a positive predictive test result for breast/ovarian cancer.

The GDP Legal Study examined both consumer allegations of GD and third party responses by analyzing cases that came before antidiscrimination tribunals and other relevant bodies in Australia. ${ }^{15}$ Only a relatively small number of cases were identified, unsurprising given perceived barriers to pursuing legal redress identified in the Consumer Study. , $^{3,4}$

This article reports findings from the Verification Project. This involved an in-depth investigation of particular cases of alleged GD with an aim to verify such cases through an integrated approach to findings from the Consumer, Third Party, and Legal Studies within the GDP. The process of verification refers to establishing the truth or correctness of the issue in question by examination or demonstration. ${ }^{16}$ 


\section{MATERIALS AND METHODS}

\section{Ascertainment of sample}

\section{Consumer study3,4}

Of the 93 asymptomatic respondents to the Consumer Study survey who reported specific incidents of alleged negative treatment in a range of domains, 56 consented to interview with Taylor et al. ${ }^{3}$ to further discuss their survey responses and the possibility of verification. Eighteen of $56(32 \%)$ reported incidents that were identified as potentially verifiable and were sent consent forms and information sheets relevant to the verification component of the GDP.

\section{Genetics health professionals}

Three genetics health professionals provided information to the GDP team of alleged negative treatment experienced by their patients.

\section{Processes of verification \\ Interview, document, and secondary analysis}

After receipt of consent, consumers were interviewed by Barlow-Stewart. They were asked to provide details of the alleged GD incidents, including all contact history and available correspondence and records with the third party. Data identified through the GDP Third Party and Legal System Studies in regard to any of these cases was also analyzed.

\section{Direct contact with third parties (insurers and financial advisers)}

All contact with insurers named by consumers in relation to alleged discrimination was facilitated by the senior policy officer of the Insurance and Financial Services Association of Australia, the body representing all Australian Prudential Regulation Authority registered life insurers. ${ }^{17}$ The policy officer contacted the named insurer, provided them with an Information Sheet and Consent Form regarding the Verification Project and advised that the GDP team wished to seek their organization's perspective regarding the case of GD that had been reported against it, their account of what had occurred and rationale for all actions that had been taken. Where financial advisers were the named relevant third party, the GDP team made direct contact with them, providing information about the project and seeking their consent and participation.

It was agreed that neither consumers nor third parties would receive any follow-up information in relation to a case; that individuals alleging discrimination would not be provided with the third party's response to those allegations nor advice as to any course of action they should or could take; and that third parties would not be provided with any information about the individual alleging discrimination other than that for which they have expressly given permission. The interest of each party would thereby be protected and there would be no legal ramifications arising from collection of this research data.

After the insurer's consent had been received, details of the consumer's name, copy of their informed consent, relevant insurance policy numbers, and their account of the incident were provided. After requests from the first participating insurer, consumer consent forms were revised to include a witness signatory and an additional witnessed and signed consent form for release of consumers' confidential information. These revisions became requirements for all subsequent verifications with insurers.

\section{Determination of GD criteria relating to the life insurance context}

The commercial and mutuality nature of an underwritten insurance contract means that there are obligations on the part of both insurers and applicants, guided by legislation, guidelines, and policies. ${ }^{18-20}$ Insurers must ensure that clauses in contracts are not overly broad and, where possible, more permissive options should be explored; underwriting decisions must be able to be justified on the basis of actuarial or statistical data or other relevant factor(s); and, where a medical practitioner's opinion is relevant, the practitioner must have expertise in assessing risks relevant to the particular condition such as inherited breast and/or ovarian cancer. Under the Australian insurance genetic testing policy, life insurers must not coerce applicants to have genetic testing but can require disclosure of personal or close relatives' test results of which applicants are aware. ${ }^{21}$

Each insurance-related case selected for verification was systematically examined by the GDP team to determine whether it seemed to fall outside the relevant exemption and guidelines. ${ }^{18-23}$ Advice was also sought from relevant independent experts, including informed academics, clinical, scientific, medical, actuarial, and legal experts as to whether the case in question would constitute GD as defined in the study.

\section{RESULTS}

\section{Sample}

Nineteen eligible consumers $(84 \%)$ consented to participate in the Verification Project. Three withdrew: two cited concerns regarding their own or family's future insurability, and one did not want to cause problems for their financial adviser. Relevant records or documentation were unable to be located in a further two cases. Fourteen cases comprising seven males and seven females proceeded through the verification process: 12 reported by consumers and two by genetics health professionals.

Relevant genetic conditions were breast and ovarian cancer ( $n=6$; designated BrOvC 1-6); Lynch syndrome (also known as hereditary nonpolyposis colorectal cancer; $n=2$; HNPCC 1-2); hereditary hemochromatosis ( $\mathrm{HH} 1)$; adult-onset polycystic kidney disease (ADPKD 1$)$ and Huntington disease $(n=4$; HD 1-4) (Table 1). All consumers were asymptomatic for the relevant condition, had no past or present health problems that would influence their risk assessment and appropriate screening, surveillance, and risk-reducing strategies were being used for all cases where relevant.

\section{Verifying alleged GD}

Table 1 provides summary data for each case and the related verification processes. This included interviews with consumers $(n=12)$ and health professionals $(n=5)$; facilitated discussions and correspondence with named insurers $(n=4)$; discussion with a financial adviser $(n=1)$; analysis of documentation provided by consumers $(n=8)$; analysis of data ascertained from insurance applications collected by the insurance industry in the GDP Third Party Study $(n=4)$ and from documentation sourced through the GDP Legal Systems Study $(n=2)$.

Full details of the incident reports and verification responses are in Appendix, Supplemental Digital Content 1, http://links.lww.com/A711 and Appendix, Supplemental Digital Content 2, http://links.lww.com/A712.

\section{Incidents of alleged GD}

Reported incidents occurred between 1998 and 2005. Genetic test results were relevant for eight cases and the incidents occurred $0-3$ years after genetic testing. 
Table 1 Cases taken through the verification process: Interview with consumer (IC); interview with health professional(s) (IHP); documentation (D); data from the GDP Third Party Study (T); data from the GDP Legal Systems Study (L)

\begin{tabular}{|c|c|c|c|c|c|}
\hline Case & Gender & Age (range) & Genetic test result/year & Incident year(s) & Verification process \\
\hline \multicolumn{6}{|c|}{ Breast/ovarian cancer } \\
\hline $\mathrm{BrOvC}-1$ & $\mathrm{~F}$ & $45-50$ & $B R C A 1$ mutation 2001 & 2002 & IC, discussion with financial adviser \\
\hline $\mathrm{BrOvC}-2$ & F & $30-35$ & $B R C A 1$ mutation 2000 & 2001 & $\begin{array}{l}\text { IC, IHP, D, facilitated discussion with } \\
\text { insurer }\end{array}$ \\
\hline $\mathrm{BrOvC}-3$ & M & $30-35$ & $B R C A 2$ mutation 1998 & 1998 and 2001 & $\mathrm{IC}, \mathrm{D}$ \\
\hline $\mathrm{BrOvC}-4$ & M & $45-50$ & $B R C A 2$ mutation 2002 & 2003 & IC, D, facilitated discussion with insurer \\
\hline $\mathrm{BrOvC}-5$ & F & $30-35$ & BRCA1 mutation 2003 & $2002 / 2003$ & IC, facilitated discussion with insurer \\
\hline BrOvC-6 & F & Unknown & N/A & 2005 & IHP, D \\
\hline \multicolumn{6}{|c|}{ Lynch syndrome } \\
\hline HNPCC-1 & M & $45-50$ & Mismatch repair mutation 2001 & 2002 & $\mathrm{IC}, \mathrm{D}$ \\
\hline HNPCC-2 & F & $30-35$ & Mismatch repair mutation 1999 & 2002 & IC, facilitated discussion with insurer \\
\hline \multicolumn{6}{|c|}{ Hereditary hemochromatosis } \\
\hline HH-1 & F & $25-30$ & HFE mutation 2001 & 2002 & IC, IHP, T \\
\hline \multicolumn{6}{|c|}{ Adult-onset polycystic kidney disease } \\
\hline ADPKD-1 & M & $35-40$ & N/A & 2001 & IC, IHP, T \\
\hline \multicolumn{6}{|c|}{ Huntington disease } \\
\hline HD-1 & M & $40-45$ & N/A & 1999 & $\mathrm{IC}, \mathrm{D}, \mathrm{T}$ \\
\hline HD-2 & M & $25-30$ & N/A & 2000 & $\mathrm{IC}, \mathrm{D}, \mathrm{T}$ \\
\hline HD-3 & F & $40-45$ & N/A & 2000 & $\mathrm{IC}, \mathrm{D}, \mathrm{L}$ \\
\hline HD-4 & M & $45-50$ & N/A & 2000 & IHP, D, L \\
\hline
\end{tabular}

Eleven cases involved life insurance applications, particularly for income protection and trauma polices where a claim can be made for an onset of certain illnesses including cancer (Table 2); financial advisers facilitated 8/11 applications. One incident related to an application for workers compensation insurance and one to an application for early release from prison. Two incidents described fear of GD in insurance and/or employment that impacted on access to genetic testing.

\section{Life insurance}

\section{Inability to access insurance or nonstandard underwriting decisions including overly broad exclusion clauses}

Incidents included denial of an increase in the amount covered on an existing trauma insurance policy for a woman with a BRCA1 mutation (Case $\mathrm{BrOvC}-1$ ); denial of income protection and/or trauma insurance for a woman with a BRCA1 mutation (Case $\mathrm{BrOvC}-2$ ), a man with a $B R C A 2$ mutation (Case $\mathrm{BrOvC}-3$ ) and a man with a mismatch repair mutation (Case HNPCC-1). In the latter case, as a result of this denial, he took out annually renewable sickness and accident insurance which was revised after 2 years to remove claims for onset of any illness.

In 2003, a man with a $B R C A 2$ mutation (Case $\mathrm{BrOvC}-4$ ) was offered income protection and trauma insurance that excluded claims for all forms of cancer. The insurer's chief medical officer responded that the decision relied upon a 1997 source $^{24}$ and noted that "the BRCA2 genetic mutation may manifest not only with breast cancer but also with ovarian cancer, prostate cancer, pancreatic cancer and melanoma. [Additionally], since the radiotherapy and/or chemotherapy may be needed to treat most comorbidity malignancies, the risk of secondary cancer, of undetermined type, may well occur later in life." Experts consulted by the GDP viewed this exclusion clause as overly broad.

\section{Changing underwriting decisions over time}

Two women with BRCA1 mutations who applied for income protection to the same insurer in 2000 and 2003 were given different decisions: denial of income protection and trauma insurance cover for Case BrOVC-2 and exclusion of only breast cancer from income protection insurance for Case $\mathrm{BrOvC}-5$. The Senior Policy Officer from the Insurance and Financial Services Association explained that the reason for the difference in decision making was the availability of updated information by 2003 on which the underwriters would have relied.

\section{Reversal of nonstandard decisions after intervention by a genetics health professional}

Intervention by a genetics health professional in reversing adverse decisions to standard rate was seen in two cases: first, a woman homozygous for an HFE mutation predisposing her to hereditary hemochromatosis (Case $\mathrm{HH}-1)$; and second, a man 
Table 2 Summary of incidents of negative treatment

\begin{tabular}{|c|c|c|c|}
\hline Case & Context of incident & Influencing factor & Reported negative treatment \\
\hline \multicolumn{4}{|c|}{ Breast/ovarian cancer } \\
\hline BrOvC-1 & $\begin{array}{l}\text { Income protection insurance, increase } \\
\text { cover on existing trauma policy }\end{array}$ & Genetic test result & $\begin{array}{l}\text { Denial of income protection and increased } \\
\text { trauma cover; financial adviser suggested } \\
\text { children not have testing until could } \\
\text { afford to take out insurance }\end{array}$ \\
\hline $\mathrm{BrOvC}-2$ & $\begin{array}{l}\text { Income protection and trauma } \\
\text { insurance }\end{array}$ & Genetic test result & $\begin{array}{l}\text { Exclusion of claims for all forms of } \\
\text { cancer according to financial adviser; } \\
\text { insurer response was that insurance } \\
\text { was denied }\end{array}$ \\
\hline $\mathrm{BrOvC}-3$ & $\begin{array}{l}\text { Income protection insurance; sickness } \\
\text { and accident insurance }\end{array}$ & Genetic test result & $\begin{array}{l}\text { Denial of income protection insurance } \\
\text { according to financial adviser; } \\
\text { limitation of claim in sickness and } \\
\text { accident insurance to accidents only }\end{array}$ \\
\hline BrOvC-4 & $\begin{array}{l}\text { Income protection and trauma } \\
\text { insurance }\end{array}$ & Genetic test result & $\begin{array}{l}\text { Exclusion of claims for all forms of } \\
\text { cancer according to financial adviser }\end{array}$ \\
\hline BrOvC-5 & Income protection insurance & Genetic test result & $\begin{array}{l}\text { Reversal on appeal of exclusion of claims } \\
\text { for all forms of cancer to breast cancer } \\
\text { only }\end{array}$ \\
\hline
\end{tabular}

BrOvC-6 Access to genetic testing for relatives

Fear of insurance and employment genetic discrimination for relatives

Genetic test result

Genetic test result

Genetic test result

Family history-normal renal ultrasounds normal at $>30$ years old

Family history-affected maternal grandfather with unaffected at-risk mother aged late $80 \mathrm{~s}$

Family history_father's age of onset late $70 \mathrm{~s}$

Family history

Family history
Prevention of $B R C A$ mutation search on biopsy samples from deceased relative due to their destruction in accordance with instructions in the wil

Denial of insurance according to financial adviser

Denial of insurance according to financial adviser

Unable to increase cover but reversal of decision following intervention by genetics professional

Policies offered with $100 \%$ loading and benefit period reduced by 5 years

Denial of insurance according to financial adviser unless he could prove negative for HD mutation

Death cover offered with loading but all other insurance denied; coerced by insurer to complete genetic testing on blood taken for test

Coerced to have genetic testing to prove injury not due to symptoms of HD

Coerced to have genetic testing to prove would not develop HD as a condition of parole with a family history of polycystic kidney disease but with normal renal ultrasounds at ages 30 and at 36 (Cases ADPKD1). In the first case, the insurer was told that there was no statistical evidence to support the decision to decline an increase in cover on an existing policy. In the second, evidence from the literature was provided, showing that the normal renal ultrasounds indicated he was not at risk for polycystic kidney disease so that the decision to offer income protection insurance with 
$100 \%$ loading and a reduced benefit period of 5 years was unsupported.

\section{Coercion to have genetic testing and failure to account for other relevant factors such as family history}

Two consumers at 50\% risk for Huntington disease felt pressured to have testing. A man whose at-risk mother was unaffected in her late 80 s required income protection, trauma, and death insurance for his business (Case HD-1). The insurance industry data confirmed his perception: after his application for insurance at standard rate with disclosure of his negative test result: the insurer noted "if [the test result was] positive, cover would have been declined." The genetics health professional involved in the testing noted that his risk based on his family history was "vanishingly small."

In Case HD-2, the man worked in the financial industry. He had had testing but did not wish to access the results. He was eventually offered death cover but other insurance was declined. The insurance industry data noted that for this application "test results not made available (client not aware of results). Rated on family history only"; and, after later testing negative for the mutation and his insurance was offered at standard rate: "[cover was] previously declined due to family history of Huntington's disease so has had test." The fact that he had had to argue assertively over many months that, because he had not yet received the results, his application should be assessed on family history alone was not included in the insurance industry data.

\section{Mismatch of consumer allegation and insurer response}

In three cases, consumers reported being told information about their applications by financial advisers that was not verified by the insurers.

One woman was told that her income protection and trauma insurance application had been offered with an exclusion of all cancers (BrOvC-2). However, after referral to a reinsurer, the insurer noted that they informed the financial adviser involved that the application was declined but exclusion was never suggested. The woman believed that the decision to decline was due to her refusal to accept the cancer exclusion clause.

Another woman believed that an adverse decision, because of her BRCA1 mutation, had been reversed as a result of her appealing directly to the insurer. The original decision was to offer her income protection insurance that excluded claims for all forms of cancer; it was changed to an offer of exclusion of breast cancer only (BrOvC-5). However, the insurer stated that the original decision was always that a breast cancer only exclusion would apply. Although the body of the letter sent to the adviser noted an offer of cover with exclusion of "any cancer or malignant tumors of the breasts," the title of the letter had been "cancer/tumor exclusion." The adviser admitted he had only looked at the title and had not read the letter in full.

In Case HNPCC-2, the woman had undertaken preventive surgeries and strategies and she was distressed to learn from her financial adviser that no company was prepared to offer her the insurance because "the risk is too high" because of her genetic condition. However, the insurer response was that the two companies were waiting for further information to clarify her risk and the applications did not proceed. It was not possible to confirm with the adviser whether, or if, he had actually proceeded with the applications.

\section{Fear of GD in life insurance}

In Case BrOvC-1, a financial adviser informed the adult children of a woman with a $B R C A 1$ mutation that they would find accessing required business insurance difficult or very expensive and advised delaying genetic testing until they could afford insurance - which would be some considerable time in the future.

In Case BrOvC-6, the woman had a strong family history of breast cancer that was suggestive of inherited susceptibility. In these families, it is first necessary to find the causative mutation in an affected family member. The only relative that could enable such testing had left instructions in her will that her biopsy samples be destroyed after her death because she feared that if a mutation was found by testing the samples, her family members would be subjected to GD in insurance and employment. However, that meant that these unaffected family members would not be able to access predictive genetic testing if a mutation was found and they wished to do so.

\section{GD in other contexts}

In two cases, consumers were coerced to have genetic testing after advice of nongenetics health professionals. A woman's workers' compensation claim after a fall at work was questioned because of her family history of Huntington disease (HD-3). She was pressured to have testing to prove the fall was not an early sign of the condition.

A Corrections Board adjudicating a parole application for a man with a family history of Huntington disease requested he undertake testing to establish whether he was affected (HD-4). The medical report noted that "the disease is not immediately evident but he is a little hoarse and this may have some significance in that speech defects often occur somewhat earlier than other signs." The man did not wish to have genetic testing in the prison environment but felt pressured to prove that he would not be "a danger to the community" if released early from prison.

\section{DISCUSSION}

The verification of consumer and health professional-reported incidents confirms the anecdotal evidence that GD is occurring $^{2}$ and that fear of such discrimination is impacting on accessing genetic testing. The requirements of the verification process in terms of consumers being prepared to come forward, the retention of relevant documentation and the willingness of third parties to participate meant that the incidents investigated were primarily confined to life insurance products, particularly in regard to cover for the onset of illness and its impact on income. However, other incidents show that pressure is being exerted to have genetic testing in contexts where their use and interpretation was questionable.

\section{Risk-rated insurance}

The majority of verified cases involved life-not healthinsurance, reflecting that Australia has a national health system. ${ }^{25}$ In Australia, life insurers are currently granted an exemption within antidiscrimination legislation (s.46 Disability Discrimination Act 1992) ${ }^{18}$ which permits them to discriminate against individuals applying for new or updated life insurance on the basis of imputed or future disability provided they can justify these underwriting decisions on actuarial, statistical or other grounds. To inform the underwriting, applicants must disclose all known information relevant to their risk, ${ }^{19}$ such as personal and family past or present health problems and genetic test results; some life insurance application forms also now have specific questions about genetic testing. ${ }^{26}$ Failure to do so may render the contract invalid. ${ }^{19}$ Once the contract has been finalized, most life insurance products are guaranteed renewable irrespective of the change in health status of the applicant, and 
the protection provided by the policy will continue as long as payments are made. However, products sold by general insurers such as travel and cover for sickness and accidents, require renewal on an annual basis; at each renewal, any new information relevant to the risk has to be disclosed.

Although only about $30 \%$ of Australians take out one or more life insurance policies, and the number of applications where a predictive genetic test result is disclosed is currently small, ${ }^{14}$ life insurance plays a significant role in providing a means of ensuring financial security for one's family to cover additional costs associated with the onset of illness. ${ }^{17}$ Limitations on access to this financial support based on inappropriate use or interpretation of genetic information is an important issue.

Moreover, life insurance is a global industry and premium income was predicted to increase worldwide by $5.4 \%$ in $2007 .{ }^{27}$ In $2004,77 \%$ of US citizens owned some type of life insurance. ${ }^{28}$ Although the US 2008 Genetic Information Nondiscrimination $\mathrm{Act}^{29}$ addressed the use of predictive genetic test results in employment and health insurance, their use in life insurance, disability insurance, or long-term care insurance is not covered. ${ }^{30}$ Several authors have recently called for a reevaluation of these exempt areas given the swift advances in genetics science. ${ }^{30}$ The experience of Australian consumers may provide some guidance in any such reevaluation.

\section{Underwriting practice}

Underwriting decisions over a 3 year period changed with further information available as illustrated by the cases of two women with the same genetic test result: from outright denial to breast cancer exclusion. Understanding is still developing about the penetrance risks for breast cancer and the influence of both genetic and lifestyle factors. ${ }^{31-34}$ This affirms earlier concerns that in some cases genetic science is not yet developed sufficiently to rely upon for purposes of underwriting in insurance. ${ }^{35}$

In regard to familial cancers and Huntington disease, clinicians are urged to take note of the family history, the nature and site of the mutation with which the risk is expected to correlate. ${ }^{36-38}$ Insurers need to be similarly aware, and avoid the repetition of the discriminatory actions seen in this data with lack of account of the impact of family history on risk assessment in two cases related to Huntington disease.

Increasingly there will be defined correlations between phenotype and genotype ${ }^{39}$ that will influence predicted age of onset and severity and thereby impact on prediction and screening and surveillance protocols, all pertinent to underwriting. For example, $B R C A$ germ-line genetic testing is likely to be offered to guide treatment when a breast or ovarian cancer is first diagnosed, and may not be associated with a family history. ${ }^{40,41}$ If a relevant mutation is identified and this information is communicated within the family, the woman's blood relatives will be obliged to disclose in insurance application that they have a genetic risk for breast and/ovarian cancer. This will impact on their assessment of risk by underwriters and so it is essential that these assessments are made with appropriate actuarial modeling. New genetic tests are also being developed and offered in specialist services for conditions such as cardiac disease but until the actuarial modeling is calculated, their use in underwriting needs to be treated with caution so as to avoid a repetition of the experiences reported here, or similar.

The tests should be subject to review by an expert panel as occurs in the United Kingdom. ${ }^{42,43}$ Such practice would limit the use of those tests which do not meet the criteria for underwriting while actuarial modeling and the accumulation of other reliable statistical data on which insurers can rely can take place. ${ }^{44}$ The burden of this for life insurers may not be high given the currently small number of applications where a genetic test result is disclosed. ${ }^{14}$ Importantly, even in the United Kingdom, $81 \%$ of life insurers surveyed indicated that they do not take any positive (adverse) genetic test results into account, even those they are permitted to take into account under a moratorium on their use that is in place until 2011.45

Risk assessment when underwriting trauma and income protection insurance does have higher levels of scrutiny because of covering claims for onset of illness. However, in this data and in a similar case reported from the analysis of the insurance industry data, where a breast and/or ovarian cancer susceptibility genetic test was undertaken by a man for the benefit of other family members, ${ }^{14}$ the decisions were to impose a broad cancer exclusion for the trauma and income protection applications. Such underwriting decisions also have the potential to limit participation in testing for anyone trying to establish financial security for their families. ${ }^{46,47}$ Significantly, an overly broad exclusion means the decision is beyond the protective scope of the antidiscrimination exemption under law, notwithstanding that a nonstandard decision of some kind may be warranted in the case of some insurance products. ${ }^{18,20,23}$

The complexity and hierarchy of decision making in the underwriting of insurance applications means that input is sought from those with varying levels of expertise: underwriters at senior and chief levels, the chief medical officer or another medical doctor using information and opinions provided in underwriting manuals or from reinsurers who provide expert advice. ${ }^{14,48}$ Several cases illustrate that decisions were not made with appropriate up to date information or advice. In one case the imposition of an overly broad cancer exclusion clause for a male with a $B R C A 2$ mutation was based on information that was 3 years old - a significant time lapse in this dynamic field. In the polycystic kidney disease case, the original reinsurer's decision was reversed when a genetics health professional provided data from the literature. Moreover, in the insurance industry data, three cases were identified where reinsurers advised that overly broad exclusions clauses be imposed. ${ }^{14}$

It would seem appropriate therefore for insurers to consult genetics health professionals when underwriting decisions are made on applications where a genetic test result has been disclosed. There is a case to be made that responsibility lies with insurers to justify adverse decisions and therefore the onus is on them to seek expert clinical input in relevant cases as discussed more fully in the GDP Third Party Study report. ${ }^{14}$

The coercion by an insurer to access genetic test results - the denial of the right "not to know"-reported by a man regarding Huntington disease testing, underscores the importance of promotion of the genetic testing policy within the Australian life insurance industry which states that this should not occur. ${ }^{21}$ This incident occurred in 2000, and the Insurance and Financial Services Association asserted in a submission to the Australian Government Inquiry in $2002^{49}$ that coercion would not now occur because of the implementation of the Genetic Testing Policy. ${ }^{21}$ Continuing education and promotion of that policy is important to ensure good ethical practice. Adoption of the policy by the general insurance industry seems warranted.

\section{Training and education in the financial industry}

Miscommunication or possible lack of communication on the part of financial advisers was identified in three cases in this data. Inappropriate advice about genetic testing was given by a financial adviser to the adult children of a mother with an identified breast cancer predisposing mutation. It is clear that enhanced education and training are essential for this profes- 
sional group who are important players in ensuring that consumers access insurance products that are best for them.

A key aspect of the raft of reforms recommended by the Australian Federal Inquiry is for improved education of the sector to overcome misunderstandings which may be the basis for life insurance discrimination. ${ }^{50}$ This, together with other reforms proposed, is a crucial step in improving the quality of decision making in this area and building consumer trust and confidence in the process.

\section{Broad applications of genetic testing}

Relevant to the issues of life insurance discussed above, patients, and participants in research studies where predictive test results are provided, will need to be aware of the implications for their and their family member's insurability when choosing to have these tests. In Australia, resources are available to provide information about genetics and insurance and need to be promoted in clinical, genetic counseling, and research settings. ${ }^{17,51}$

However, discrimination resulted from the broader use of genetic testing in two verified cases: tests were requested for Huntington disease in the context of a workers' compensation claim and to inform a parole application. In another case ascertained in the Legal System Study, a successful complaint brought under the Disability Discrimination Act 1992 (Cth) ${ }^{18}$ was based on misunderstanding of the meaning of sickle cell trait: a policeman of mixed Aboriginal and African ethnicity alleged discrimination in his employment after he was placed on restricted duties because of his sickle cell trait. ${ }^{15}$ Increasingly, use of genetic tests will move out of the specialized clinical genetics services to primary care. Unless they are used and interpreted appropriately, genetic tests can lead to discrimination.

\section{Consumer proactivity}

Consumers who perceive they may be the subject of GD need to question the evidence that has underpinned the decisions that have been made and to challenge findings. Genetic counselors and clinicians should inform consumers about the need to be proactive in involving them or other medical specialist in supporting their life insurance applications. Resources like those available in Australia ${ }^{51}$ and the United Kingdom ${ }^{52}$ can assist: where they are not available, their development seems warranted. Importantly, intervention by genetics health professionals may reverse inappropriate adverse decisions if they are aware of the situation.

The findings of the GDP Consumer and Legal Systems Studies $^{3,4,15}$ underscore a notable lack of uptake of available industry-based and legal remedies by those who may have experienced GD and that there are perceived barriers to complaining or taking action including lack of relevant knowledge about how or where to undertake such courses of action. It is therefore imperative that strategies are developed to promote awareness and provide support for consumers to overcome the formidable barriers to taking this adversarial path.

\section{Policy development}

There is a lack of trust by consumers that insurers would appropriately use genetic test results in Australia ${ }^{53}$ and the United States ${ }^{54}$ so policy development in this area is required for the benefit of both insurers and consumers.

Trust might be fostered through transparency of decision making by insurers, consultation with relevant experts, and better communication of the reasons for the decisions, including making clear the extent to which a genetic test result influenced the policy offer. In the insurance industry dataset, for example, underwriting in $51 \%$ of the cases involved consideration of some factor in addition to the genetic test result. ${ }^{14}$

There are complex economic, legal, and social issues surrounding the use of genetic information in life insurance underwriting. ${ }^{55}$ In the United States and United Kingdom, governments have taken a different approach to the regulation of genetic information in insurance. ${ }^{56,57}$ The legislative route has been adopted in the United States, most recently in regard to health insurance and employment with a call for further work to be done in the area of life insurance. ${ }^{30}$ In the United Kingdom, a cooperative approach to the definition of genetic risk and its regulation has been used with consumer groups, insurers, and policy makers accepting that genetic information should be understood in the context of the disease and family history, and decisions about its use should be based on its accuracy as an indicator of its predictability for future health. ${ }^{43}$ It has been reported that the UK insurance industry regards the moratorium as a very successful, pragmatic solution which recognizes the need to protect consumers alongside the rights and responsibilities of insurers. ${ }^{58}$ The UK Human Genetics Commission has been effective in shaping this arrangement, working closely with consumers and expert groups, the insurance industry and relevant Government Departments. ${ }^{58}$

In Australia, the United Kingdom, and United States, the insurance industry has resisted legislation limiting their right to use genetic information in underwriting, citing the risk that adverse selection would impact on the industry's financial viability. ${ }^{57-62}$ While in Australia and the United Kingdom a cooperative strategy has been adopted by the industry to date, the incentive for future use of genetic tests in underwriting by insurers worldwide is likely to increase, particularly as they become cheaper, more widely used and their predictability more reliable. The Australian Government accepted in 2005 the recommendations of the Federal Inquiry that, as a matter of priority, procedures should be established through an appropriate body (currently the National Health and Medical Research Council ${ }^{59}$ ) to assess and make recommendations on whether genetic tests should be used in underwriting mutually rated insurance, having regard to their scientific reliability, actuarial relevance, and reasonableness. ${ }^{11}$ To date this has not been implemented.

\section{Challenges and limitations}

Providing an opportunity for third parties to give their account of circumstances surrounding alleged cases of GD contributes significantly to filling the research gap in this area. Given the commercial and contractual arrangements in place between consumers and third parties like insurers and employers, participating in the process of verification for this research study required significant trust by both parties. Consumer fears of further negative treatment by third parties and legal and ethical concerns of third parties made verification particularly complex and challenging.

Although verification in insurance is difficult, it is arguably even more complex in other areas such as in the context of a continuing employment relationship. Although the incidents reported in the Consumer Study were in the insurance, employment, health service, and family domains, ${ }^{3,4}$ the cases verified have an insurance focus largely because of the support we had in that sector from the Senior Policy Manager with the Investment and Financial Services Association, the late Mr. David Mico, who was a valued member of the Expert Reference Group and facilitated access to and discussion with life insurers in 
Australia. Without that support it is unlikely that verification would have been achieved.

Participation in the verification process is a daunting prospect for many consumers and may have contributed to the small number of cases reported here. Verification is a complex and multistaged process with high attrition at each stage; this contributes to the significant challenges of substantiating that GD has actually occurred and to the ostensibly low prevalence of such discrimination. Moreover, consumers are reportedly already adopting strategies to manage the risks of perceived discrimination, perhaps limiting the numbers who expose themselves to potentially discriminatory practices. ${ }^{63}$ Many consumers avoid applying or put their life insurance in place before having genetic testing, if they can afford the impact of adverse underwriting generated by disclosure of their family history. $3,4,5,14,63$

Whether the cases presented in this article are likely to be representative of industry practice more broadly is open to question. It needs to be acknowledged that the verified incidents occurred up to 2003. The Life Insurance and Financial Association in Australia has been collecting data on all applications where a genetic test result has been disclosed since 1999. The data has been analyzed by the Australian Institute of Actuaries and they report that there are only a small number of applications with few if any problems. ${ }^{14}$ However, it would seem that there is some underreporting: six of the seven verified familial cancer consumer-reported cases involving life insurance applications were not documented in the industry data report for the relevant period.

\section{CONCLUSION}

Although verification of GD is challenging and inherently difficult, a significant consequence of these first verified findings is to dispel any criticisms concerning doubts about its existence and prevalence. Life insurance was the main context within which GD occurred in this Australian investigation, but this does not discount the possibility of it happening in health or other risk-rated insurance in other countries. The regulation and policies governing the use of genetic information in underwriting will be country specific and challenging with the need to balance the economic, legal, and ethical concerns within different political systems. ${ }^{56,57}$

The prevention of GD in insurance is an important and timely issue. These verified cases of GD may offer some guidance internationally to the development of policies regarding use and interpretation of genetic test results, communication of decisions to consumers and education and training within the financial industry. Increasing availability of predictive genetic tests also underscores the need for widespread education to ensure that clinicians, researchers, and consumers are aware of relevant implications and that testing utilization will be for maximum benefit and minimal harm.

\section{ACKNOWLEDGMENTS}

The project was supported by Australian Research Council Discovery Project no. 0208853. This work would not have been completed without the commitment of the Senior Policy Manager, Investment and Financial Services Association Ltd., the late Mr. David Mico. The authors thank all other members of the Expert Reference Group that advised the researchers, those individuals who participated in the study and the staff of clinical genetics services around Australia.

\section{REFERENCES}

1. Taylor SD, Otlowski MF, Barlow-Stewart KK, Treloar SA, Stranger M, Chenoweth K. Investigating genetic discrimination in Australia: opportunities and challenges in the early stages. New Genet Soc 2004;23:225-239.

2. Barlow-Stewart K, Keays D. Genetic discrimination in Australia (2001). J Law Med 2004;8:250.

3. Taylor SD, Treloar SA, Barlow-Stewart KK, Stranger M, Otlowski M. Investigating perceptions and experiences of genetic discrimination. I. A large-scale survey of clinical genetic service consumers in Australia. Clin Genet 2008;74:20-30.

4. Taylor S, Treloar S, Barlow-Stewart K, et al. Investigating genetic discrimination in Australia: perceptions and experiences of clinical genetics service clients regarding coercion to test, insurance and employment. Aust J Emerg Techn Soc 2007;5:63. Available at: www.swinburne.edu.au/ajets.

5. Geller LN. Current developments in genetic discrimination. In: Alper JS, Ard C, Asch A, Beckwith J, Conrad P, Geller L, editors. The double-edged helix: social implications of genetics in a diverse society. Baltimore: Johns Hopkins University Press, 2002:267.

6. Geller LN, Alper JS, Billings PR, Barash CI, Beckwith J, Natowicz MR. Individual, family, and societal dimensions of genetic discrimination: a case study analysis. Sci Eng Ethics 1996;2:71-88

7. Hall MA, McEwen JE, Barton JC, et al. Concerns in a primary care population about genetic discrimination by insurers. Gen Med 2005;7: 311-316.

8. Low L, King S, Wilkie T. Genetic discrimination in life insurance: empirical evidence from a cross sectional survey of genetic support groups in the United Kingdom. BMJ 1998;317:1632-1635.

9. Hendricks A. Genetics, human rights and employment: American and European perspectives. Med Law 1997;16:557-565.

10. Wertz DC. Genetic discrimination - an overblown fear? Nat Rev Genet 2002; 297:196-197.

11. Australian Law Reform Commission \& Australian Health Ethics Committee of the National Health \& Medical Research Council NHMRC (ALRC/AHEC/ AHEC/AHEC), 2003. Essentially yours: the protection of Human Genetic Information in Australia. Available at: http://www.alrc.gov.au. Accessed July 2008 .

12. Otlowski M, Taylor S, Barlow-Stewart K. Major study commencing into genetic discrimination in Australia. J Law Med 2002;10:41-48.

13. Otlowski M, Stranger M, Taylor S, et al. Practices and attitudes of Australian employers in relation to the use of genetic information: report of a national study. Comp Labor Law Policy $J$ In press.

14. Otlowski M, Barlow-Stewart K, Taylor S, Stranger M, Treloar S. Investigating genetic discrimination in the Australian life insurance sector: the use of genetic test results in underwriting, 1999-2003. J Law Med 2007;14:367396.

15. Otlowski MF, Taylor SD, Barlow-Stewart KK, Stranger M, Treloar SA. The use of legal remedies in Australia for pursuing allegations of genetic discrimination: findings of an empirical study. Int J Discrim 2007;9:3.

16. Oxford Concise Dictionary. 6th ed. London: Oxford Univ Press, 1976.

17. Investment and Financial Services Association (IFSA). Available at: http:// www.ifsa.com.au/index.aspx. Accessed August 2008

18. Disability Discrimination Act (Cth) s 46. Available at: http://www.austlii. edu.au/au/legis/cth/consol_act/dda1992264/. Accessed May 2008.

19. Insurance Contracts Act 1984 (Cth), ss 13, 21. Available at: http://www. austlii.edu.au/au/legis/cth/consol_act/ica1984220/. Accessed May 2008

20. Human Rights and Equal Opportunity Commission (HREOC), 2005. Disability standards and guidelines: guidelines for providers of insurance and superannuation. Available at: http://www.hreoc.gov.au/disability_rights/standards/ Insurance/insurance adv.html. Accessed May 2008

21. Investment and Financial Services Association (IFSA). Standard No 11.00 Genetic Testing, cll 10.1 and 10.3. Available at: http://www.ifsa.com.au. Accessed May 2008.

22. Otlowski M. Implications of genetic testing for Australian insurance law and practice. Centre for law and genetics, 2001. Occasional Paper No. 1.

23. Otlowski M. Resolving the conundrum: should insurers be entitled to access genetic test information? Ins Law J 2000;11:193-215.

24. Scheuner MT. Online management of breast diseases. 1997. Available at: http://www.breastdiseases.com/genebr.htm. Accessed March 2008.

25. Australian Commonwealth Department of Health and Ageing, Private Health Insurance Administration Council. Available at: http:// www.phiac.gov.au/. Accessed March 2008.

26. Lynch E, Doherty RJ, Gaff CL, Macrae FA, Lindeman GJ. Cancer in the family and genetic testing: implications for life insurance. Med J Aust 2003; 179:480-483

27. Swiss Re sigma No 3, 2008. World insurance in 2007: emerging markets leading the way. Available at: http://www.swissre.com/. Accessed August 2008.

28. American Council of Life Insurers, 2007. Life insurance fact book. Available at: http://www.acli.com. Accessed August 2008.

29. Genetic Information Nondiscrimination Act, S. 358 (GINA). Available at: http:// www.govtrack.us/congress/bill.xpd?bill=s110-358. Accessed April 2008. 
30. Hudson KJ, Holohan MK, Collins F. Keeping pace with the times-the genetics Nondiscrimination Act of 2008. N Engl J Med 2008;358:26612663.

31. National Health and Medical Research Council. Familial aspects of cancer: a guide to clinical practice. 1999. National Health and Medical Research Council. Available at: http://www.hmrc.gov.au/publications/synopses/_files/ cp67.pdf. Accessed January 30, 2009.

32. Antoniou A, Pharoah PD, Narod S, et al. Average risks of breast and ovarian cancer associated with BRCA1 or BRCA2 mutations detected in case series unselected for family history: a combined analysis of 22 studies. Am J Hum Genet 2003;72:1117-1130.

33. Chen S, Iversen ES, Friebel T, et al. Characterization of BRCA1 and BRCA2 mutations in a large United States sample. J Clin Oncol 2006;24:863-871.

34. Antoniou A, Pharaoh P, Easton D, Evans DG. BRCA1 and BRCA2 cancer risks. J Clin Oncol 2006;24:3312-3313.

35. Spiteri G. Genetic testing and its implications for Australian insurance law. James Cook Uni Law Rev 2000: 96.

36. Antoniou A, Spurdle A, Sinilnikova OM, et al. Common breast cancerpredisposition alleles are associated with breast cancer risk in BRCA1 and BRCA2 mutation carriers. Am J Hum Genet 2008;82:937-948.

37. U.S.-Venezuela Collaborative Research Project; Wexler NS, Lorimer J, Porter J, et al. Venezuelan kindreds reveal that genetic and environmental factors modulate Huntington's disease age of onset. Proc Nat Acad Sci USA 2004;101:3498-3503.

38. Brinkman R, Mezei MM, Theilmann J, Almqvist E, Hayden MR. The likelihood of being affected with Huntington disease by a particular age, for a specific CAG size. Am J Hum Genet 1997;60:1202-1210.

39. Bertario L, Russo A, Sala P, et al; Hereditary Colorectal Tumor Registry. Multiple approach to the exploration of genotype-phenotype correlations in familial adenomatous polyposis. J Clin Oncol 2003;21:1698-1707.

40. Malone K, Daling J, Neal C, et al. Frequency of BRCA1/BRCA2 mutations in a population-based sample of young breast carcinoma cases. Cancer 2000;88:1393-1402.

41. Moller P, Evans D, Reis M, et al. Surveillance for familial breast cancer: differences in outcome according to BRCA mutation status. Int $J$ Cancer 2007; 121:1017-1020.

42. Association of British Insurers. Available at: http://www.abi.org.United Kingdom/. Accessed February 2008.

43. HM Government and the Association of British Insurers, Concordat and Moratorium on Genetics and Insurance, March 2005

44. Joly Y, Knoppers BM, Godard B. Genetic information and life insurance: a 'real' risk? Eur J Hum Genet 2003;11:561-564.

45. Association of British Insurers (ABI). ABI Genetic Testing and Insurance, Compliance Report and Data Analysis for 2003. Available at: http://www. abi.org.uk. Accessed May 2008.

46. Hallowell N, Ardern-Jones A, Eeles R, et al. Men's decision-making about predictive BRCA1/2 testing: the role of the family. J Gen Couns 2005;14: 207-217.

47. Armstrong K, Calzone K, Stopfer J, Fitzgerald G, Coyne J, Weber B. Factors associated with clinical BRCA1/2 testing. Cancer Epidemiol Biomarkers 2000;9:1251-1254.

48. Regenauer A, Schmidtke J. Genetics. Basis for medicine in the 21st century; genetic testing and insurance-a global view. Munich Reinsurance Co., 1998. Munchener Ruckvericherungs-Gesellschaft, Munchen.

49. Investment and Financial Services Association, Submission G049, 14 January
2002 to the Australian Law Reform Commission \& Australian Health Ethics Committee of the National Health \& Medical Research Council NHMRC (ALRC/AHEC), 2003. Essentially yours: the protection of Human Genetic Information in Australia 2003. Available at: http://www.alrc.gov.au. Accessed March 2008.

50. Australian Law Reform Commission \& Australian Health Ethics Committee of the National Health \& Medical Research Council NHMRC (ALRC/ AHEC), 2003. Essentially yours: the protection of Human Genetic Information in Australia. Recommendations 27-10-27-11 Available at: http://www.alrc. gov.au. Accessed March 2008.

51. Centre for Genetics Education (GCE), 2003. 'Genetic Information and Life Insurance Products in Australia.' Available at: http://www.genetics.com.au/ pdf/pubs/lifeinsurance.pdf. Accessed March 2008

52. Genetic Interest Group (GIG). The template project. Availble at: http:// www.gig.org.uk. Accessed April 2008.

53. Barlow-Stewart K, Taylor S, Otlowski M. Knowing your genes. In: Wilson S, Meagher G, Gibson R, et al., editors. Australian social attitudes - the first report. Sydney: University of New South Wales Press Ltd., 2005:204-219.

54. Rothstein M. Genetics and life insurance. Medical underwriting and social policy. MA: MIT Press, 2004. ISBN 026218236X, 9780262182362.

55. Radetzki M, Radetzki M, Juth N. Genes and insurance. Ethical, legal and economic issues. UK: Cambridge University Press, 2004. ISBN 0521830907.

56. Rothstein M, Knoppers B. Legal aspects of genetics, work and insurance in North America and Europe. Eur J Health Law 1996;3:143-161.

57. Parthasarthy S. Regulating risk: defining genetic privacy in the United States and Britain. Sci Technol Hum Values 2004;29:332-352.

58. Ian Hammond Consulting Ltd for Department of Health and Department of Trade and Industry, 2008. Light touch review of the Human Genetics Commission. Final report February 2008. Available at: http://www.dh.gov.uk/en/ Publicationsandstatistics/Publications/PublicationsPolicyAndGuidance/DH_084690. Accessed May 24, 2008.

59. Australian Law Reform Commission \& Australian Health Ethics Committee of the National Health \& Medical Research Council NHMRC (ALRC/ AHEC), 2003. Essentially yours: the protection of Human Genetic Information in Australia. Recommendation 5-1. Available at: http://www.alrc.gov.au. Accessed March 2008.

60. Lemmens T. Private parties, public duties? The shifting tole of insurance companies in the genetics era. In: Thompson A, Chadwick R, editors. Genetic information: acquisition, access and control. New York: Kluwer Academic/ Plenum Publishers, 1999:31-39.

61. Investment and Financial Services Association, Submission G244, 19 December 2002 to the Australian Law Reform Commission \& Australian Health Ethics Committee of the National Health \& Medical Research Council NHMRC (ALRC/AHEC), 2003. Essentially yours: the protection of Human Genetic Information in Australia. Available at: http://www.alrc.gov.au. Accessed March 2008

62. Institute of Actuaries of Australia, Submission G105, 7 March 2002 to the Australian Law Reform Commission \& Australian Health Ethics Committee of the National Health \& Medical Research Council NHMRC (ALRC/ AHEC), 2003. Essentially yours: the protection of Human Genetic Information in Australia. Available at: http://www.alrc.gov.au. Accessed March 2008.

63. Bombard Y, Pensiner E, Decolongon J, et al. Managing genetic discrimination: strategies used by individuals found to have the Huntington disease mutation. Clin Genet 2007;71:220-231. 